ORIGINAL ARTICLE

\title{
Perceived STD risk, relationship, and health values in adolescents' delaying sexual intercourse with new partners
}

\author{
C Rosengard, N E Adler, S G Millstein, J E Gurvey, J M Ellen
}

Sex Transm Infect 2004;80:130-137. doi: 10.1136/sti.2003.006056

See end of article for authors' affiliations

......................

Correspondence to: Cynthia Rosengard, PhD, Rhode Island Hospital, Division of General Internal Medicine, Multiphasic Building, First Floor, 593 Eddy Street, Providence, RI 02903, USA; Cynthia_rosengard@ Brown.edu

Accepted for publication 16 September 2003

\begin{abstract}
Objectives: To examine the amount of time adolescents waited to have intercourse with past partners (main and casual), and intentions to delay with future partners. To determine psychosocial factors which predict delay intentions among adolescent males and females with future partners (main and casual). Methods: Adolescent STD clinic attendees were approached before clinical appointments to participate in an interview. Data from 205 participants who had previous experience with both main and casual partners were used in the current study.

Results: Adolescents waited less time to have intercourse with most recent casual than with most recent main partners $\left(\chi^{2}=31.97, p<0.0001\right)$. The amount of time waited with past partners was shorter than intended time to wait in future relationships (medians of 1 month $v 2$ months (main) $(t=3.47, p<0.0010$; medians of 2 weeks $v 1$ month (casual) $(t=6.14, p<0.0001)$ ). Factors influencing intentions to delay intercourse with future main partners differed by sex; males were negatively influenced by importance of sex in relationships, while females were positively influenced by importance of intimacy in relationships, perceived risk of STDs, and health values.
\end{abstract}

Conclusions: Implications for designing interventions for adolescent males and females are discussed.
1 $\mathrm{t}$ is estimated that by the end of 9th grade more than a third of adolescents have had sexual intercourse and that by 12th grade two thirds have become sexually active. ${ }^{1}$ Sexually active adolescents tend to have multiple sexual partners (sequential and/or concurrent) and to be inconsistent in their practice of safer sex. ${ }^{12}$ The combination of these factors places adolescents at risk for a variety of problems, including unplanned pregnancies and sexually transmitted diseases (STDs), including human immunodeficiency virus (HIV) and acquired immune deficiency syndrome (AIDS). One way that adolescents have been encouraged to reduce the risk of adverse consequences from sexual behaviour is to "get to know" their partners before having sex. ${ }^{3}$ Discussing contraceptive use contributes to a greater likelihood of actual use. ${ }^{4}$ Delaying engaging in sexual intercourse in new relationships may afford more opportunity to participate in such discussions. ${ }^{5-9}$ Delay may also result in fewer lifetime sexual partners, as longer delays before engaging in sexual intercourse may increase the length of partnerships and create wider gaps between partnerships. Furthermore, the transmission of STDs among adolescents might be reduced through wider gaps between sexual partnerships as well as reduced incidence of concurrent sexual partnerships (typically a primary or "main" partner and one or more side or "casual" partner(s))..$^{10}$

Researchers have examined a number of factors associated with delay in the onset of sexual intercourse for sexually inexperienced adolescents. ${ }^{11-15}$ One study found that, among adolescents who are contemplating their first ever intercourse, few attempts are made to assess STD risk factors in prospective partners and that time to intercourse in first relationships ranged from within 24 hours to more than 6 months, with the majority reporting between 24 hours and 2 weeks. ${ }^{16}$ Cohen and Shotland ${ }^{17}$ investigated college students' expectations about timing of first intercourse in relationships that varied according to physical attraction and emotional involvement. They found that men expected intercourse to occur after fewer dates and were more likely to expect sex in the absence of emotional closeness than women. Others have attempted to examine young adults' (typically college students') attitudes towards hypothetical targets based on the length of time the targets waited before engaging in sexual intercourse in relationships of varying degrees of commitment. ${ }^{18}{ }^{19}$ In general, findings suggest that perception of the amount of time that hypothetical individuals waited before engaging in sexual intercourse varied according to the relationship context (casual versus serious relationship). To our knowledge, no studies have directly assessed how long sexually experienced adolescents delay engaging in sexual intercourse in new relationships and what factors may be associated with the intended length of delay in future relationships.

\section{The current study}

In light of the part that relationship context appears to play in assessments of delays before engaging in sexual intercourse, and because adolescents report sexual behaviour both with partners with whom there is a relationship or special bond (main partners) and partners with whom there may be a friendship or only an acquaintance (casual partners), ${ }^{20-22}$ the current study assessed sexually experienced adolescents' past delay of sexual intercourse with their most recent main and casual partners and their intentions to delay engaging in sexual intercourse in new relationships with future partners of both types. We also examined sex differences in modifiable psychosocial factors (for example, relationship values, perceived risk of STDs, and health values) associated with intention to delay engaging in sexual intercourse with future main and casual partners. The importance placed on various aspects of relationships (that is, intimacy and sex), perceived risk of STDs, and the importance placed on health have all been found to relate to aspects of adolescent and young adult sexual decision making (for example, condom use) within different types of sexual partnerships. ${ }^{17}{ }^{23-25}$ The following research questions were addressed: (1) How long do adolescents report waiting (past delay) and intending to wait (future delay intentions) to engage in sexual intercourse in new relationships with main and casual partners? (2) Are 
there significant differences between reports of males and females of past delay behaviour and future delay intentions? (3) Which of the modifiable factors (for example, relationship values, perceived risk of STDs, and health values) are associated with males' and females' reported delay intentions with future main and casual partners?

\section{METHOD \\ Participants}

Between June 1996 and June 1998, participants were recruited by approaching consecutive adolescent patients visiting the only municipal STD clinic in San Francisco. Two hundred and five adolescents (125 females and 80 males) participated in the current study (age range 14-19 years old, mean age 17.67, SD 1.38). The ethnic/racial make-up (measured using a single item) of the sample consisted of 37\% African-American, 22\% white, 15\% Latino/Hispanic, $11 \%$ Asian American, $15 \%$ mixed race, and $<1 \%$ Native American/Alaskan or Pacific Islanders/Polynesian. Mother's education was used as a proxy for socioeconomic status. Eight per cent of the participants' mothers had not graduated from high school, $11 \%$ had some high school education, $30 \%$ had graduated from high school, 19\% had some college or technical school experience, $23 \%$ had graduated from college, $7 \%$ had some type of advanced professional degree (masters or doctoral), and $2 \%$ of the participants reported that they did not know about their mother's education.

Of the 366 adolescents originally approached for this study (all were identified as eligible through review of records before appointments), 62 (17\%) refused participation. Patients who refused to participate were asked to fill out a short, anonymous questionnaire about their demographic characteristics to assess volunteer effects. Analysis (using $t$ tests and logistic regression analyses, as appropriate) of the demographic characteristics revealed significant differences in age, sex, and race/ethnicity between adolescents who participated and those who declined. Those who refused to participate were older (mean 18.18, SD 1.03; $t=-3.00$, $\mathrm{df}=336, \mathrm{p}=0.003)$, more likely to be male $(t=3.87$, $\mathrm{df}=336, \quad \mathrm{p}=0.0001)$, and more likely to be Asian $(\mathrm{OR}=2.82,95 \% \mathrm{CI}, 1.10$ to 7.34$)$. There were no differences in mothers' education.

Of the 276 participants who provided complete data $(28$ protocols were incomplete), 205 had past experiences with both main and casual partners, so their data were used in the current analyses. Comparing the demographics of the 71 who did not have past experiences with both main and casual partners and were therefore dropped, and the remaining 205, there were no differences in age, sex, or socioeconomic status. However, among those who were excluded, there was a statistically significant difference in race/ethnicity, with more Asians and "other" race participants being excluded $\left(\chi^{2}=12.61, \mathrm{df}=4\right.$, $\mathrm{p}=0.013)$.

\section{Procedure}

\section{Recruitment}

Patients were approached and recruited by research assistants, before they saw a clinician. Patients' eligibility was verified using a short structured questionnaire. Eligibility criteria included age between 14-19 years old, English speaking ability, having engaged in vaginal or anal intercourse in the preceding 3 months, and residence within the local metropolitan area. Because California law considers adolescents under the age of 18 obtaining sex related health services to be emancipated, informed consent from parents was not required.

\section{Administration of measures}

Data for the current analyses were collected as part of a larger study examining perceived risk of STDs, perceived risk of pregnancy, and sexual decision making. ${ }^{23}$ After obtaining written informed consent, a research assistant conducted a structured interview with each participant in a private room and filled out corresponding questionnaires with the participants' answers to questions. The interview assessed demographics, partner specific perceived risk of STDs, attitudes towards condom use, perceived social norms regarding condom use, condom self efficacy, and intentions to use a condom. The relationship values, health values, and delay of initiation of sexual intercourse items were included within this interview. Participants were offered compensation of $\$ 15.00$ to participate in the interview. The study protocol was approved by the institutional review board of the University of California, San Francisco.

\section{Measures \\ Demographics}

Participants were asked to indicate their age, race/ethnicity (one item), as well as their mother's level of educational attainment (proxy for socioeconomic status).

\section{STD concern/diagnosis}

Participants were asked to indicate what their clinicians told them regarding their STD diagnosis (that is, did they have a positive STD diagnosis?) and also whether they thought that they had an STD ("Right now, do you think you have a sexually transmitted disease?"). Both items were answered either Yes or No.

\section{Partner specific condom use}

Participants were asked to indicate whether they had used a condom during their last sexual encounter with their most recent main and casual sex partners. These items were answered either Yes or No.

\section{Relationship value}

The importance of intimacy and sex in relationships was assessed using a 14 item Likert type measure, constructed for this study. Participants were asked to fill out a questionnaire on their own, indicating how important a variety of aspects of relationships with main partners are to them using a scale ranging from 1 ("not at all important," "not much," "not very strong") to 5 ("extremely important," "extremely," "extremely strong"). The questions did not ask about a specific main partner, just about main partners, in general. A factor analysis was conducted to identify items in the relationship values measure that would empirically comprise scales. The first of two factors extracted (eigen value 3.23) contained seven intimacy value items with factor loadings greater than $0.40(\alpha=0.80)$. A sample intimacy item is "How important is it to feel close to your partner?" The second factor extracted (eigen value 1.84) contained four sex value items with factor loadings greater than $0.40(\alpha=0.79)$. A sample sex item is "How important is it to have frequent sex with your partner?" Intimacy value and sex value subscales were created by taking the mean of the items for each factor. Higher numbers on these continuous scales indicate greater importance or value.

\section{Health values}

The Value on Health Scale developed by Costa et $a l^{26}$ assesses a number of domains of health that may be valued differentially by adolescents including physical fitness, sense of energy, weight control, resistance to illness, and endurance aspects of good health. Participants were asked to indicate the level of importance that they attached to each item on a 
Likert scale ranging from 1 ("not at all important") to 5 ("extremely important"). Items were standardised and combined. The internal consistency for this scale was acceptable $(\alpha=0.82)$ and similar to reliability estimates found previously $\left(\alpha=0.7^{25} ; \alpha=0.81^{26}\right)$. Again, higher numbers on this continuous scale indicate greater importance or value.

\section{Perceived risk of STDs}

All items for main and casual sex partners (five items for each partner type) began "If you have unprotected sex with a (main/casual) partner ...". The items were completed with the following statements "...how likely are you to get (an STD)?" (Responses were "not at all likely," "a little likely," "somewhat likely," "very likely," "extremely likely"), "...what are the chances out of 100 that you will get (an STD)?" (Responses ranged from $0 \%$ to $100 \%$, in increments of $10 \%)$, and "...what is the risk that you will get (an STD)?" (Responses were "no risk," "low risk," "medium risk," "high risk," "extremely high risk"), "...how strongly do you agree/ disagree that you will get (an STD)?" (Response were "disagree...a lot, a little, a medium amount" and "agree...a lot, a little, a medium amount"), "...how strongly do you agree/disagree that you will NOT get (an STD)?" (Responses were same as above, but reversed when combined with other items). We then combined items for each partner type into scales by first multiplying item responses by an appropriate ratio so responses to all items ranged from 1 to 5 . We then summed the rescaled items (perceived risk of STD (casual): $\alpha=0.82$; perceived risk of STD (main): $\alpha=0.91$ ). Higher numbers on these continuous scales (main and casual) indicate greater perceived risk.

\section{Delay of sexual intercourse}

Past delay of initiation of sexual intercourse with most recent main and casual partners was assessed using two items (one for each partner type): "How long did you wait to have sex for the first time with your most recent main (casual) partner?" Future intention to delay sexual intercourse with new main and casual partners was assessed using two items for each partner type: "How long do you plan to wait before having sex for the first time with your next main (causal) partner?" and "How long are you likely to wait before having sex for the first time with your next main (casual) partner?" Answers for both past delay and future intention to delay were $1=$ "less than 1 day," $2=$ " 1 day," $3=$ "a couple of days," $4=$ "1 week," $5=$ "2 weeks," $6=$ "3 weeks," $7=$ "1 month," $8=$ "2 months," $9=$ "3 months," and $10=$ "more than 3 months." The average of the scores for the two future intention items were used as a measure of future intention for each partner type.

\section{Partner types}

Participants were asked to indicate if they had ever had sexual partners of the following types. Main partners were described as "someone that you have sex with and you consider to be the person who you are serious about." Casual partners were described as "anyone that you have sex with but you do not consider this person to be a main partner to you. This person can be someone you've had sex with only once, or a few times, or you have sex with them on an ongoing, casual basis. The important thing, however, is that this person is not a main partner to you." Development of these definitions has been described previously. ${ }^{27}$ Following elicitation research with adolescents, follow up ratings with a different sample were assessed to ensure that these definitions were meaningful and distinct from one another. Recognising that the definitions of partner type can change over the course of relationships, we also asked participants to indicate, for each sexual partner they identified for the 6 months before the study, whether they considered them main or casual during their first sexual encounter and during their last sexual encounter.

\section{Data analysis}

To determine how long adolescents report waiting to engage in sexual intercourse in new relationships with main and casual partners (research question 1) we examined frequency distributions and medians of the delay variables. Although delay variables were measured as categorical, they were treated as continuous in some analyses for ease of interpretation. All analyses were initially conducted using categorical delay variables, but findings from these analyses did not differ from those treating delay as a continuous variable. To identify significant differences between males' and females' reports of past delay behaviour and future delay intentions (research question 2), a series of four cross tabulations (likelihood ratio $\chi^{2}$ analyses) were performed. For this and subsequent analyses, we split the four delay measures at their medians, using the total sample of males and females ( $>2$ months versus $<2$ months for main partners; $>1$ month versus $<1$ month for casual partners).

To determine what factors are associated with males' and females' reported delay intentions with future main and casual partners (research question 3), bivariate Pearson correlations between all main study variables were calculated for each sex separately. These correlations identified significant associations among relationship values, health values, perceived risk of STDs, past delay with most recent partners, and future delay intentions with new partners. Additionally, four logistic regression models were built (two each for males and females) to determine if, after controlling for age, mother's education, current STD status, concern regarding STDs, and partner specific condom use at last sex, the psychosocial variables of interest (relationship values, health values, and perceived risk of STDs) were associated with future intentions to delay engaging in sexual intercourse with new partners of each type. Median splits of the delay intention variables (calculated using the total sample of males and females) were, again, used as the outcomes for these logistic regressions because the distributions of the delay intention variables were skewed and bimodal ${ }^{28}$ and were therefore inappropriate for linear modelling.

\section{RESULTS \\ Delay in initiating sexual intercourse (past and future) and sex differences}

Reviewing the distribution of frequencies for past delay behaviour and future delay intentions (see fig 1) we observed differences between past delay behaviour and future delay intentions with main and casual partners for males and females. In general, the lengths of intended delay with future main and casual partners were longer than reported past delays with most recent main and casual partners for males and females (see table 1).

Next we examined actual differences between sexes. Again, short and long wait times are centred around the median, which tended to differ for each of the four groups (males/main, males/casual, females/main, females/casual). No differences were found when we compared males and females on past delay with main partners: roughly 50\% said they had only waited a short time (1 month or less) before having sexual intercourse with their most recent main partner. However, with past casual partners, $67.5 \%$ of males $v 40 \%$ of females reported delaying a short time (2 weeks or less) $\left(\chi^{2}=14.76, \mathrm{p}<0.0001\right)$. Similarly for future intentions to delay with a main partner, $65 \%$ of males $v 46 \%$ of females reported that they would wait a short period of time 

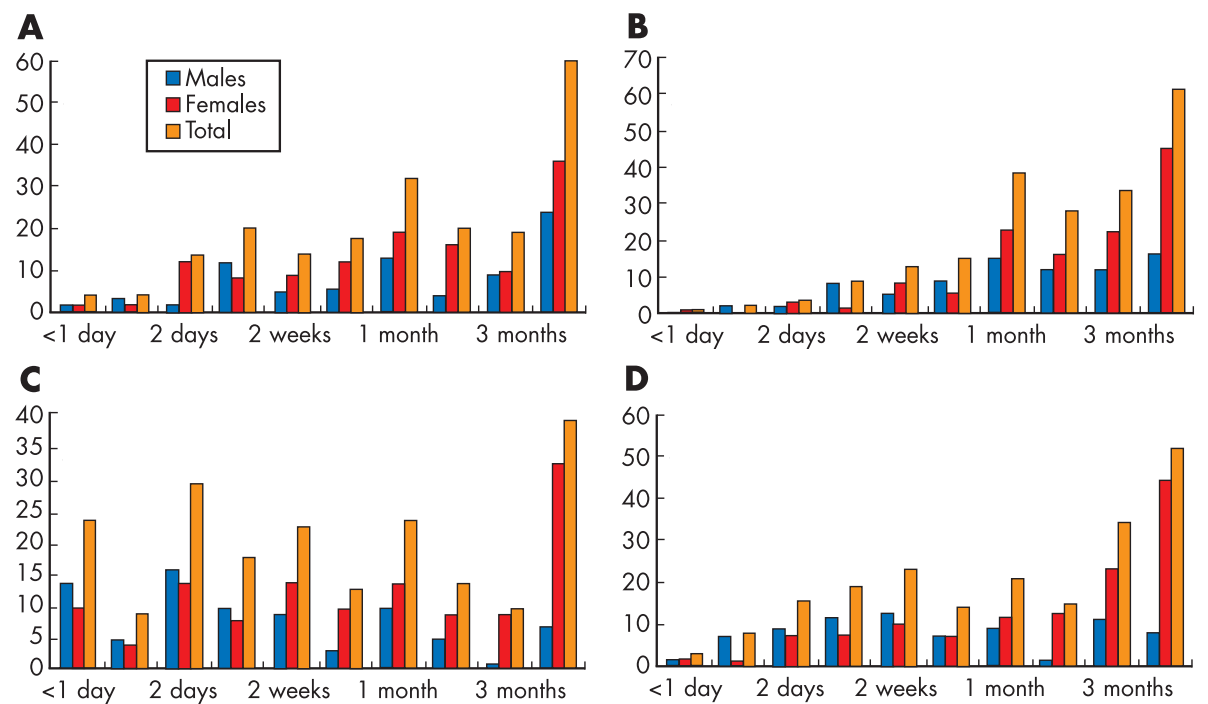

Figure 1 (A) Distribution of past delay (main partners). (B) Distribution of future intended delay (main partners). (C) Distribution of past delay (casual partners). (D) Distribution of future intended delay (casual partners).

(1-2 months or less) before having sexual intercourse $\left(\chi^{2}=6.79, p<0.01\right)$. The most striking difference in sex was in future delay intentions with casual partners, where $73.8 \%$ of males reported a short intended delay time ( 1 month or less), $v 36 \%$ of females $\left(\chi^{2}=27.81, \mathrm{p}<0.0001\right)$ (see table 2 ).

\section{Factors associated with future delay intentions}

\section{Bivariate correlations}

We examined correlations among study variables separately by sex (see table 3, males' data below the diagonal, females' data above the diagonal). For males, aside from past delay behaviour with most recent partners of both types (that is, the longer past delays, the longer intended delays), the factors that accounted for the most variance in intention to delay sexual intercourse with a future main partner were the importance of sex in their relationships (that is, the greater importance of sex, the shorter the intended delay) and the importance placed on health (that is, the greater the importance of health, the longer the intended delay). The factors that accounted for the most variance in intention to delay sexual intercourse with a future casual partner for males were past delay behaviour (that is, again, the longer past delays, the longer intended delays), the importance of health (that is, again, the greater the importance of health, the longer the intended delay) the perceived risk of contracting an STD from a casual partner (that is, the greater the perceived risk, the longer the intended delay) as well as intentions for longer delays with future main partners (that is, longer intended delays with main partners, the longer intended delays with casual partners).

For females, similar factors appeared to be at work. The perceived risk of contracting an STD from a main or casual partner (that is, the greater perception of risk, the longer the intended delay), the importance of health (that is, the greater importance of health, the longer intended delay), and past delay behaviours with main and casual partners (that is, the longer past delays, the longer intended delays) were factors that accounted for variance in females' intentions to delay sexual intercourse with main partners. Only past delay behaviour with casual and main partners, along with delay intentions with future main partners accounted for variance in females' intentions to delay sexual intercourse with casual partners. Please note that for both males and females, past delay behaviour with main and casual partners was strongly related ( $r=0.37$ for males; $r=0.42$ for females) as was future delay intentions with main and casual partners $(r=0.40$ for males; $r=0.67$ for females).

\section{Logistic regressions}

To determine whether or not these same factors would predict intentions to delay sexual intercourse in future relationships with main and casual partners, controlling for demographic (age and socioeconomic status) and STD variables (concern and current diagnosis), we conducted logistic regressions. Given earlier findings of sex differences, we built the models for males and females separately. In our analyses, we found that among the males, greater importance placed on sex in relationships with main partners decreased the likelihood of reporting intentions to delay engaging in intercourse 2 months or longer with new main partners $(\mathrm{OR}=0.37,95 \% \mathrm{CI}, 0.15$ to 0.92$)$. None of the predictor variables was significantly associated with intentions to delay intercourse with new casual partners among males (see table 4). Among the females, placing greater importance on their health ( $\mathrm{OR}=2.50,95 \% \mathrm{CI}, 1.27$ to 4.93 ), placing greater importance on intimacy in relationships with main partners

Table 1 Medians of past delay behaviour and intentions to delay sexual intercourse with main and casual partners (sex comparisons)

\begin{tabular}{|c|c|c|c|c|}
\hline & \multicolumn{2}{|l|}{ Main } & \multicolumn{2}{|l|}{ Casual } \\
\hline & Past & Intended & Past & Intended \\
\hline $\begin{array}{l}\text { Males } \\
\text { Females } \\
\text { Overall }\end{array}$ & $\begin{array}{l}1 \text { month } \\
1 \text { month } \\
1 \text { month }\end{array}$ & $\begin{array}{l}2 \text { months } \\
2-3 \text { months } \\
2 \text { months }\end{array}$ & $\begin{array}{l}1 \text { week } \\
1 \text { month } \\
2 \text { weeks }\end{array}$ & $\begin{array}{l}2 \text { weeks } \\
2-3 \text { months } \\
1 \text { month }\end{array}$ \\
\hline
\end{tabular}


Table 2 Sex differences in past delay behaviour and intentions to delay sexual intercourse with main and casual partners

\begin{tabular}{|c|c|c|c|c|c|c|c|c|}
\hline & \multicolumn{4}{|l|}{ Main } & \multicolumn{4}{|l|}{ Casual } \\
\hline & \multicolumn{2}{|l|}{ Past } & \multicolumn{2}{|l|}{ Future* } & \multicolumn{2}{|l|}{ Past** } & \multicolumn{2}{|l|}{ Future $^{* *}$} \\
\hline & Males & Females & Males & Females & Males & Females & Males & Females \\
\hline Short delay & $43(54 \%)$ & $63(50 \%)$ & $52(65 \%)$ & $58(46 \%)$ & $54(68 \%)$ & $50(40 \%)$ & 59 (74\%) & $45(36 \%)$ \\
\hline Long delay & $37(46 \%)$ & $62(50 \%)$ & $28(35 \%)$ & 67 (54\%) & $26(32 \%)$ & $75(60 \%)$ & $21(26 \%)$ & $80(64 \%)$ \\
\hline
\end{tabular}

$(\mathrm{OR}=3.81,95 \% \mathrm{CI}, 1.17$ to 12.39$)$, and perceiving a higher risk of contracting an STD from a main partner $(\mathrm{OR}=1.14$, 95\% CI, 1.04 to 1.25 ) increased the likelihood of reporting intentions to delay engaging in intercourse 2 months or longer with new main partners. Greater importance placed on sex in relationships with main partners decreased the likelihood of reporting intentions to delay engaging in intercourse 2 months or longer with new main partners $(\mathrm{OR}=0.50,95 \% \mathrm{CI}, 0.26$ to 0.98$)$ and 1 month or longer with new casual partners ( $\mathrm{OR}=0.42,95 \% \mathrm{CI}, 0.20$ to 0.88 ) among females (see table 4 ).

\section{Exploratory analysis}

To examine whether there might be sex differences in the process of partner definition that might account for differences in delay behaviour and intentions between adolescent males and females, a $\chi^{2}$ analysis was conducted. Participants were categorised according to the proportion of their most recent sexual relationships in which partner definition did not differ between first and last sexual encounter (main remained main and casual remained casual) and the percentage of relationships where partner definitions changed between first and last sexual encounter (main became casual and casual became main). Although males were more likely to report casual partners who remained casual and less likely to report partners who started out casual and became main, than females, we found no overall significant differences between males and females in the process of partner definitions $\left(\chi^{2}=3.19, p=0.36\right)$ (see table 5).

\section{DISCUSSION}

\section{Length of delay in engaging in sexual intercourse}

This sample of sexually active adolescents reported that they had engaged in sex earlier with their most recent casual partners than with their most recent main partners. One possibility is that adolescents define their relationships (as main or casual) before the initiation of sexual intercourse, with definitions of relationships being related, in part, to how quickly sexual intercourse is initiated. An alternative explanation is that early initiation of intercourse may affect how relationships are defined retrospectively. A study of the impact on relationship development of engaging in sexual intercourse for the first time among sexually active college students ${ }^{29}$ revealed that when the quality of the relationship was a deciding factor in engaging in intercourse, there were more positive effects on the relationship. In contrast, when females felt pressured to engage in first intercourse, the impact on the development of the relationship was more negative. Casual partnerships are characterised by relatively short periods of time elapsing before the initiation of sex (for example, 1-2 weeks). While our data do not allow us to draw conclusions about the circumstances surrounding initial intercourse, the exploratory analyses we conducted indicate that male adolescents may be more likely to enter into casual relationships that they intend to remain casual while female adolescents may redefine relationships that started out casual as main later on.

The difference between reported past behaviour and future intentions suggests that adolescents know they ought to wait longer before initiating sexual intercourse than they have waited in the past. While sexual risk reduction interventions often include the message to "know your partner" before having sex, ${ }^{30}{ }^{31}$ the length of time before adolescents feel comfortable enough to engage in sex with new partners has not often been examined. Consistent with previous research ${ }^{17}$ the current investigation found that, on average, adolescents are engaging in sex between 1 week and 2 months after beginning a new relationship. Whether this amount of time allows adolescents to discuss contraceptives, sexual history, and STD status of their partners is unknown. Although not directly measured in our study, encouraging longer delays might reduce exposure to risk through fewer lifetime sexual partners and/or fewer concurrent partnerships and might also results in fewer STD diagnoses and fewer unwanted pregnancies among sexually experienced adolescents.

\section{Sex differences in past delay and future delay intentions}

For male and female adolescents, future intentions to delay are similar to past delay behaviour with their most recent

Table 3 Bivariate correlations between main study variables (males $(n=80)$ : below diagonal $\backslash$ females $(n=125)$; above diagonal)

\begin{tabular}{|c|c|c|c|c|c|c|c|c|c|}
\hline & Intimacy & Sex & $\begin{array}{l}\text { Health } \\
\text { values }\end{array}$ & PRSTD-M & PRSTD-C & Past delay-M & Past delay-C & Delay intent-M & Delay intent-C \\
\hline Intimacy & 1.00 & 0.15 & 0.02 & -0.13 & 0.03 & 0.17 & 0.02 & 0.17 & 0.05 \\
\hline Sex & 0.19 & 1.00 & -0.01 & -0.17 & -0.03 & -0.01 & -0.04 & -0.16 & -0.14 \\
\hline Health values & 0.18 & 0.03 & 1.00 & 0.09 & $0.19^{*}$ & $0.18^{*}$ & 0.09 & $0.28^{* *}$ & 0.17 \\
\hline PRSTD (main) & -0.20 & 0.07 & -0.09 & 1.00 & $0.57^{* *}$ & 0.14 & 0.17 & $0.20^{*}$ & 0.18 \\
\hline PRSTD (casual) & -0.04 & $-0.28^{* *}$ & 0.07 & $0.54^{\star *}$ & 1.00 & 0.16 & 0.07 & $0.31^{* *}$ & 0.12 \\
\hline Past delay (main) & 0.09 & $-0.28^{* *}$ & 0.21 & 0.12 & $0.34^{* *}$ & 1.00 & $0.42^{* *}$ & $0.54^{* *}$ & $0.48^{\star *}$ \\
\hline Past delay (casual) & -0.08 & $-0.29 * *$ & -0.06 & 0.14 & $0.31^{* *}$ & $0.37^{* *}$ & 1.00 & $0.45^{\star *}$ & $0.61^{* *}$ \\
\hline Delay intent (main) & 0.14 & $-0.29^{* *}$ & $0.22^{*}$ & 0.03 & 0.21 & $0.69^{* *}$ & $0.33^{* *}$ & 1.00 & $0.67^{\star *}$ \\
\hline Delay intent (casual) & 0.18 & -0.16 & $0.27^{\star *}$ & -0.04 & $0.25^{\star}$ & $0.42^{* *}$ & $0.56^{\star *}$ & $0.40^{\text {** }}$ & 1.00 \\
\hline
\end{tabular}


Table 4 Odds ratios of factors associated with future intentions to delay intercourse with new main and casual partners (males and females)

\begin{tabular}{|c|c|c|c|c|c|c|c|c|}
\hline \multirow[b]{3}{*}{ Predictors } & \multicolumn{4}{|l|}{ Males } & \multicolumn{4}{|c|}{ Females } \\
\hline & \multicolumn{2}{|l|}{ Main } & \multicolumn{2}{|c|}{ Casual } & \multicolumn{2}{|l|}{ Main } & \multicolumn{2}{|c|}{ Casual } \\
\hline & OR & $(95 \% \mathrm{Cl})$ & $\overline{O R}$ & $(95 \% \mathrm{Cl})$ & OR & $(95 \% \mathrm{Cl})$ & $\overline{O R}$ & $(95 \% \mathrm{Cl})$ \\
\hline Age & 0.70 & (0.39 to 1.3$)$ & 1.34 & (0.57 to 3.1$)$ & 0.97 & (0.71 to 1.3$)$ & 0.82 & $(0.59$ to 1.1$)$ \\
\hline Socioeconomic status $†$ & 0.77 & (0.54 to 1.1$)$ & 1.22 & (0.83 to 1.8$)$ & 0.92 & $(0.71$ to 1.2$)$ & 0.90 & (0.64 to 1.3 ) \\
\hline STD concern† & 1.49 & $(0.33$ to 6.6$)$ & 2.96 & (0.50 to 17$)$ & 2.06 & $(0.60$ to 7.0$)$ & 0.57 & (0.15 to 2.1$)$ \\
\hline STD Dx† & 1.59 & $(0.73$ to 3.4$)$ & 0.87 & $(0.51$ to 1.5$)$ & 0.31 & $(0.08$ to 1.2$)$ & 0.46 & $(0.08$ to 2.7$)$ \\
\hline Condom use $†$ & 0.88 & $(0.24$ to 3.2$)$ & 1.39 & $(0.28$ to 7.0$)$ & 1.43 & $(0.56$ to 3.7$)$ & 1.73 & $(0.64$ to 4.7$)$ \\
\hline Sex value & $0.37^{*}$ & $(0.15$ to 0.92$)$ & 0.50 & $(0.17$ to 1.4$)$ & $050^{*}$ & (0.26 to 0.98$)$ & $0.42^{*}$ & $(0.20$ to 0.88 ) \\
\hline Intimacy value & 1.83 & $(0.61$ to 5.5$)$ & 2.68 & (0.65 to 11$)$ & $3.81^{*}$ & (1.17 to 12.4 ) & 1.30 & $(0.42$ to 3.9$)$ \\
\hline Health values & 2.80 & $(0.87$ to 9.0$)$ & 3.64 & $(0.89$ to 14$)$ & $2.50^{\text {** }}$ & (1.27 to 4.9$)$ & 1.48 & $(0.72$ to 3.1$)$ \\
\hline Perceived risk of STD & 1.06 & (0.94 to 1.2 ) & 1.16 & (0.97 to 1.4 ) & $1.14^{\star \star *}$ & (1.04 to 1.3 ) & 1.04 & (0.93 to 1.2 ) \\
\hline
\end{tabular}

†Variables entered as categorical (remaining variables entered as continuous).

${ }^{*} \mathrm{p}<0.05 ;{ }^{* *} \mathrm{p}<0.01$.

main relative to casual partners (that is, males intend longer delays with main partners than with casual partners while females intend to delay similarly with both types of partners). The sex differences in our participants' past delay behaviour with casual partners and future delay intentions with casual partners raises the question of whose intentions to delay get enacted in casual sexual relationships.

Female adolescents have been found to have more difficulty initiating discussions about contraceptive use than male adolescents ${ }^{6}$ and their attitudes towards AIDS related discussions with sexual partners do not predict subsequent safer sex behaviour. ${ }^{32}$ A sample of female young adults in Belgium was found more likely to want to protect themselves from sexual risk by abstaining from sex and using condoms than their male counterparts, but were less likely to succeed in attaining their safer sex goals when they perceived their partners to be more dominant in their relationships. ${ }^{33}$ However, a recent study of adolescent STD clinic attendees found that although males reported greater intimacy power and greater decision making power in their sexual relationships than females did, sex was not associated with getting one's way with respect to using condoms. ${ }^{34}$ These sex differences in other sexual behaviours, in combination with our findings of sex differences in past delay and future delay intentions, suggest that risk reduction interventions geared toward adolescents should include a focus on balancing each partner's desire for longer delays in engaging in intercourse in new relationships and encouraging greater comfort and skills in making these desires known in new relationships. Such efforts might allow for more equitable negotiation of the timing of engaging in sex in new relationships.

Sex differences in predictors of future delay intentions For males, placing greater importance on the role of sex in relationships reduced the likelihood of reporting intentions to delay longer with new main partners and health values increased the likelihood of intentions to delay longer with new casual partners. For females, greater importance placed on health, greater importance placed on intimacy in relationships, and greater perceived risk of STDs from main partners all increased the likelihood of reporting intentions for longer delays with future main partners, while the importance placed on sex reduced the likelihood of longer delays. These findings, among sexually experienced adolescents, support previous work that indicates that young men and women are motivated to have sex for different reasons-males report "enhancement motives" (including pleasure and sexual enjoyment), while females report primarily "intimacy motives" (including strengthening emotional bonds and for love), and that enhancement motives are related to greater sexual risk taking, while intimacy motives are related to less risk taking. ${ }^{35-37}$

The finding that health values influenced decision making regarding delays with main partners only, among females, is in contrast with our previous findings that indicated that health values were related to intentions to use condoms (another protective sexual behaviour) with casual partners only. ${ }^{25}$ Perhaps, for females, the salience of health with respect to relationships with main partners is greater in the beginning of relationships (when decisions regarding the timing of initial intercourse are being contemplated), while the salience of health in relationships with casual partners is greater while making ongoing decisions regarding protective sexual behaviours.

\section{Study limitations}

Our study has limitations. Because our study sample was a sexually experienced adolescent group who attended an urban STD clinic in an AIDS epicentre, our results may not generalise to other adolescent populations who are not yet sexually active, who have health insurance and access to more healthcare resources (and would, therefore, not attend a STD clinic), or who live in other geographical areas. Our measures employed rating scales instead of open ended questions assessing the length of past delay and length of intended delays with future main and casual partners. As discussed by Schwarz, ${ }^{38}$ the manner in which we posed the questions and the response categories that we chose might have influenced the answers participants gave. However, because we contextualised the items by asking about delay behaviour with their most recent main and casual partners, the effects on retrospective reports were probably minimised.

Table 5 Combinations of partner definitions of most recent sexual partners at first sex/ last sex (sex comparisons)

\begin{tabular}{lllll}
\hline & Main/main & Casual/casual & Main/casual & Casual/main \\
\hline Females & $56(44.8 \%)$ & $20(16.0 \%)$ & $9(7.2 \%)$ & $40(32 \%)$ \\
Males & $36(45 \%)$ & $20(25.0 \%)$ & $4(5.0 \%)$ & $20(25 \%)$ \\
\hline
\end{tabular}




\section{Key messages}

- 205 adolescents provided information on past delay of initiating sexual intercourse in new relationships with main and casual partners, psychosocial variables, and future delay intentions with both partner types

- We found differences (1) in past delay behaviour between partner types, (2) between past and future delay, and (3) in the factors that predict future delay between males and females

- Encouraging adolescents to have longer delays before initiating sexual intercourse in new relationships and recommending discussions of sexual history and STD testing during such delays may reduce exposure to STDs

Because we restricted our sample to those adolescents who reported previous experience with both main and casual partners, the number of males in our sample may have minimised our statistical power and ability to detect relationships among variables for males where they actually existed. We also acknowledge that the definitions of sexual partner type (main and casual) may be simplified and that the category of casual partnerships includes a variety of possible relationship contexts (for example, one night stands, flings, or sexual acquaintances). However, recent qualitative and quantitative research ${ }^{23} 29$ suggests that the concept of "main" partners is robust among adolescents and clearly differences in attitudes, expectancies, and values exist based on the dichotomy of main and non-main sexual partner types.

\section{Implications for interventions and future research}

These findings suggest the importance of stressing health considerations regarding safer sex in sexual risk reduction interventions with adolescent males and females. Reinforcing the importance of health and discussing the realistic assessment of partner STD risk in sexual risk reduction interventions may further encourage young men and women to delay the onset of intercourse and to encourage the use of condoms ${ }^{26}$ when they are sexually active. The more female adolescents valued intimacy in their relationships the longer their intended delay with future main partners. In contrast, the more males valued sex in their relationships, the shorter their intended delay with future main partners. Directly addressing the value of sex and intimacy in primary sexual relationships in interventions and providing education on alternative ways of being sexual and satisfying intimacy needs with a primary partner before engaging in intercourse (including vaginal, anal, and oral forms of intercourse) will allow adolescents of both sexes to identify healthier choices and encourage longer delays with main partners.

Future research should examine additional factors that may influence the timing of engaging in sexual intercourse in adolescent relationships, especially in identifying additional motivations for engaging in sexual intercourse with casual partners. Additional exploration of whether discussions of contraceptives, sexual history, and STD status are taking place during reported delays with both main and casual partners are important steps in understanding the impact of delaying engaging in sexual intercourse with new partners for adolescents.

\section{ACKNOWLEDGEMENTS}

CR was supported by the National Institutes of Mental Health Training Grant (grant No MH 19091), and the research was supported by the National Institute of Allergy and Infectious
Diseases (grant No AI36986) and the Maternal and Child Health Bureau Training Grant (grant No MCJ000978A). The authors wish to thank the adolescents who participated in the Perceived Risk Project.

\section{CONTRIBUTORS}

CR conceived of the research questions and was responsible for writing the manuscript; NA, SM, and JE developed the larger project from which the current study's data were drawn; all have contributed to writing/editing the manuscript; JG assisted in framing and running the statistical analyses for the project and has had input into writing the manuscript.

\section{Authors' affiliations}

C Rosengard, Division of General Internal Medicine, Department of Medicine, Rhode Island Hospital, Brown University School of Medicine, Providence, RI, USA

N E Adler, S G Millstein, University of California, San Francisco, CA, USA

J E Gurvey, J M Ellen, Division of General Pediatrics and Adolescent Medicine, Department of Pediatrics, Johns Hopkins School of Medicine, Baltimore, MD, USA

\section{REFERENCES}

1 Centers for Disease Control and Prevention. Youth risk behavior surveillance-United States, 2000. Morbidity and Mortality Weekly Report 2002:1-64.

2 Alan Guttmacher Institute. Teenagers' sexual and reproductive health. New York: AGI, 2001

3 US Department of Health and Human Services. Surgeon general's report on acquired immune deficiency syndrome. Rockville, MD: US DHHS, 1986.

4 Tschann JM, Adler NE. Sexual self-acceptance, communication with partner, and contraceptive use among adolescent females: a longitudinal study. J Res Adolesc 1997;7:413-30.

5 Cobb B. Communication types and sexual protective practices of college women. Public Health Nursing 1997;41:293-301.

6 Coleman L, Ingham R. Exploring young people's difficulties in talking about contraception: How can we encourage more discussion between partners? Health Educ Res 1999;14:741-50.

7 Fisher JD, Fisher WA. Changing AIDS-risk behavior. Psychol Bull 1992;111:455-74.

8 Rickman RL, Lodico M, DiClemente RJ, et al. Sexual communication is associated with condom use by sexually active incarcerated adolescents. $J$ Adolesc Health 1994; 15:383-8.

9 Shoop DM, Davidson PM. AIDS and adolescents: the relation of parent and partner communication to adolescent condom use. J Adolesc 1994; 17:137-48.

10 Rosenberg MD, Gurvey JE, Adler N, et al. Concurrent sex partners and risk for sexually transmitted diseases among adolescents. Sex Transm Dis 1999;26:208-12.

11 Carvajal SC, Parcel GS, Banspach SW, et al. Psychosocial predictors of delay of first sexual intercourse by adolescents. Health Psychology 1999:18:443-52.

12 Dilorio C, Kelley M, Hockenberry-Eaton M. Communication about sexual issues: mothers, fathers, and friends. J Adolesc Health 1999;24:181-9.

13 Dittus PJ, Jaccard J, Gordon VV. Direct and nondirect communication of maternal beliefs to adolescents: adolescent motivations for premarital sexual activity. J Appl Soc Psychol 1999;29:1927-63.

14 Meschke LL, Zweig J, Barber L, et al. Demographic, biological, psychological, and social predictors of the time of first intercourse. J Res Adolesc 2000;10:315-38.

15 Miller KS, Clark LF, Wendell DA, et al. Adolescent heterosexual experience: a new typology. J Adolesc Health 1997;20:179-86.

16 Ingham R, Woodcock A, Stenner K. Getting to know you-young people's knowledge of their partners at first intercourse. J Commun Appl Soc Psychol 1991;1:117-32.

17 Cohen LL, Shotland Lance R. Timing of first sexual intercourse in a relationship: expectations, experiences, and perceptions of others. J Sex Res 1996;33:291-9.

18 Bettor L, Hendrick S, Hendrick C. Gender and sexual standards in dating relationships. Personal Relationships 1995;2:359-69.

19 Isaac S, Bailey R, Isaac W. Perceptions of religious and nonreligious targets who participate in premarital sex. Social Behavior and Personality 1995;23:229-33.

20 Katz B, Fortenerry JD, Zimet G, et al. Partner-specific relationship characteristics and condom use among young people with sexually transmitted diseases. J Sex Res 2000;37:69-75

21 Howard M, Fortenerry JD, Blythe $M$, et al. Patterns of sexual partnerships among adolescent females. J Adolesc Health 1999:24:300-3.

22 Misovich SJ, Fisher JD, Fisher WA. Close relationship and elevated HIV risk behavior: Evidence and possible underlying psychological processes. Rev Gen Psychol 1997;1:72-107

23 Ellen JM, Adler NE, Gurvey JE, et al. Has the perception of risk failed as a variable because it is too general? The case of sexually transmitted diseases. J Appl Soc Psychol 2002;32:648-63. 
24 Eyre SL, Hoffman V, Millstein SG. The gamesmanship of sex: A model based on African American adolescent accounts. Medical Anthropology Quarterly 1998; 12:1-23.

25 Rosengard C, Adler NE, Gurvey JE, et al. Protective role of health values in adolescents' future intentions to use condoms. J Adolesc Health $2001 ; 29: 200-7$

26 Costa F, Jessor R, Donovan EJ. Value on health and adolescent conventionality: a construct validation of a new measure in problem-behavior theory. J Appl Soc Psychol 1989;19:841-61.

27 Ellen JM, Cahn S, Eyre SL, et al. Types of adolescent sexual relationships and associated perceptions about condom use. J Adolesc Health 1996; 18:417-21.

28 MacCallum R, Zhang S, Preacher KJ, et al. On the practice of dichotomization of quantitative variables. Psychol Methods 2002;7:19-40.

29 Cate RM, Long E, Angera JJ, et al. Sexual intercourse and relationship development. Family Relations 1993;42:158-64.

30 Kelly JA, Kalichman SC. Increased attention to human sexuality can improve HIV-AIDS prevention efforts: key research issues and directions. J Consulting Clin Psychol 1995;63:907-18.
31 Lewis JE, Malow MR, Ireland JS. HIV/AIDS risk in heterosexual college students a review of a decade of literature. J Am College Health 1997;45:147-57.

32 Feeney JA, Ryan SM. Attachment style, assertive communication, and safersex behavior. J Appl Soc Psychol 1999:29:1964-83.

33 Buysse A. Oost Van. 'Appropriate' male and female safer sexual behavior in heterosexual relationships. AIDS Care 1997;9:549-61.

34 Tschann JM, Adler NE, Millstein SG, et al. Relative power between sexual partners and condom use among adolescents. J Adolesc Health 2002;31:17-25.

35 Cooper ML, Shapiro MC, Powers AM. Motivations for sex and risky sexual behavior among adolescents and young adults: a functional perspective. J Personality Soc Psychol 1998;75:1528-58.

36 Regan PC, Dreyer SC. Lust? love? status? young adults' motives for engaging in casual sex. J Psychol Human Sexuality 1999:11:1-25.

37 Taris TW, Semin GR. Gender as a moderator of the effects of the love motive and relational context on sexual experience. Arch Sex Behav 1997;26:159-80.

38 Schwarz N. Self-reports: how the questions shape the answers. Am Psychol 1999:54:93-105.

\section{$\mathrm{ECHO}$}

\section{Ethicist says doctors are right to help couples with HIV have children}

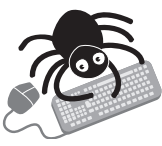

Please visit the Sexually Transmitted Infections website [www. stijournal.com for a link to the full text of this article. nfertility specialists have the right to help couples with HIV have children, according to one ethical view. They, like all doctors, must "do no harm," but ethical arguments exonerate them if the children are infected.

HIV infection in babies is a serious issue: most rapidly progress to AIDS and death or long term illness and poor quality of life until death in adolescence. So do the specialists' actions constitute recklessness-conscious and unjustified risk taking?

The risk of HIV infection from an infected man to his female partner and children is negligible if assisted conception includes precautions like sperm washing whereas for an infected woman the risk of vertical transmission of HIV to the child is $1-2 \%$. The risk of disease or disability with assisted conception in uninfected infertile couples is thought to be $3-5 \%$, similar to that in the general population. Infertility specialists are not blamed for such outcomes, so they cannot be deemed reckless if the offspring are affected in HIV positive couples.

Fertility specialists' input in assisted conception differs in fertile and infertile HIV positive couples. They are fulfilling their duty of care with fertile couples by cutting the risk of infection to the child and unaffected parent. They have a duty to help infertile couples, and their significant input with infertile over fertile HIV positive couples fulfils that moral obligation. They are responsible for any affected child, but there is no question of recklessness as the additional risk is so low.

A Journal of Medical Ethics 2003;29:321-324.

\section{....and others agree to help for HIV discordant couples}

O thers support helping HIV discordant couples have children with their own eggs and sperm through in vitro techniques-at least couples in which the man is HIV positive and the woman negative. They cite the 300 children already born to such couples with help from assisted reproductive technologies: neither children nor their mothers have become HIV positive.

Risk to offspring is paramount and may include long term effects of zidovudine and other antiviral treatments whose safety is questionable. Zidovudine does have a record of harming fetuses, but denying fertility treatment on this basis alone would be unjust as many women may have diseases requiring treatment throughout pregnancy-like epilepsy-for which there are no safety data. In fact most drugs have never been evaluated in pregnancy. However, zidovudine integrates into the host genome, with possible but unknown implications for the child and scope for heritable germline alterations, which are concerns.

HIV discordant couples are different from couples who are affected by other terminal illnesses or genetic conditions because of the added risks of infecting the woman and the child and the wider potential public health risk to healthcare workers and other patients undergoing fertility treatment.

On balance, though, offering assisted conception to these couples contravenes no ethical principles and seems to do more good than harm. Arguably, denying treatment might raise the potential for harm-from unprotected sex-but situations of particular risk-say of involving a surrogate mother-justify careful scrutiny and maybe denial.

A Journal of Medical Ethics 2003;29:325-329. 